\title{
The golden age of Drosophila research at the Universidade de São Paulo (USP): A testimonial on the decades 1940-1950
}

\author{
Luiz Edmundo de Magalhães* and Carlos Ribeiro Vilela \\ Departamento de Genética e Biologia Evolutiva, Instituto de Biociências, \\ Universidade de São Paulo, São Paulo, SP, Brazil.
}

\begin{abstract}
This article is a testimonial written by the first author regarding the research work performed with Drosophila between 1943 and 1959, at the Departamento de Biologia Geral of the Universidade de São Paulo (USP), which permitted the building of a nucleus of excellence. This research work, focused on the systematics and population genetics of the Neotropical species, began during the first of Dobzhansky's six visits to USP. Special attention was given to the multinational megaprojects conducted during his longer stays, from August 1948 to July 1949 and from June 1955 to July 1956. The role played by the Rockefeller Foundation is duly remembered, and so is the undeniable contribution brought by Dobzhansky, to the establishment of several laboratories dedicated to research in the field of natural population genetics and to the qualification of human resources. On the other hand, important "backstage" episodes are retrieved which were omitted in the official history and occurred from the planning to the execution of the project, carried out on the Angra dos Reis islands. Special attention was given to the relationship problems which resulted from Dobzhansky's, the leader's, difficult personality and contributed to the failure of the second and last multinational project.
\end{abstract}

Key words: Departamento de Biologia Geral, FFCL, Rockefeller Foundation, population genetics, Theodosius Dobzhansky.

Received: September 3, 2013; Accepted: November 28, 2013.

Introduction: The Foundation of the Universidade de São Paulo and the New Perspective of Scientific Development in the State of São Paulo

The foundation of the Universidade de São Paulo (USP) [University of São Paulo] in 1934, performed by the then government-appointed intervener in the state, Dr. Armando de Salles Oliveira, who hired several European scientists to chair the different university teaching disciplines, can easily be considered as the true driving force for the development of scientific research in the state of São Paulo in the various fields of knowledge. In addition, it filled a huge gap in education by providing the formation of high school teachers. Until then, these positions were occupied, in part, by graduates in other professions who took the risk of teaching to complement their earnings. Most of the times, however, since there were no other candidates, these positions were filled by rather unqualified persons, resulting in an education of very doubtful quality. Only after the foundation of the Faculdade de Filosofia, Ciências e Letras

Send correspondence to Carlos Ribeiro Vilela. Departamento de Genética e Biologia Evolutiva, Instituto de Biociências, Universidade de São Paulo, Rua do Matão, travessa 14, n. 321, 05508090 São Paulo, SP, Brazil. E-mail: crvilela@ ib.usp.br.

*In memoriam.
(FFCL) [School of Philosophy, Sciences and Letters] this problem was gradually overcome. The FFCL brought together, as chairs, a great variety of fields of human knowledge, from philosophy, human and biological sciences, geology, chemistry, physics and mathematics to letters. It was a central institution, the cellula mater of the University, around which the schools for professional teaching in the different fields grouped together.

This was the model by which the Natural History Course was set up, comprising the chairs of General Biology, Botany, Animal Physiology, Geology and Paleontology, Mineralogy and Petrography, and Zoology.

In its beginnings and for another few years, the number of students attending the courses offered by the FFCL was small, which in a way was good for better learning, as if the classes were private lessons. Moreover, when these students showed interest and ability, they had a great chance to be hired to fill the many teaching positions as assistants. Others went to fill high school teaching openings, thus significantly improving the education in the state of São Paulo. It is worth mentioning here that the state government maintained a network of schools for which the teaching openings started to be filled by means of a rigorous public contest and that the wages of teachers, both of public and of private schools, were highly rewarding. Teachers enjoyed a remarkable position in society, being treated with great re- 
spect and consideration. All this represented a major progress in the qualification of youngsters, with reflections on the development of society.

Furthermore, the big novelty brought by the recently founded FFCL, of great importance for its role as a driving agent of progress, was the starting of research, generating new knowledge as part of the education of its students. So, this was the scenario in which the Departmento de Biologia Geral [Department of General Biology] or, as it was initially named, the Cadeira de Biologia Geral [Chair of General Biology] was inserted, with the purpose of making science and offering courses of excellent quality even by international standards.

By bringing to São Paulo a great number of university teachers from Europe to fill the openings of the new school, the State Government achieved, in a single step, a huge quality leap in education. At that time, the European, mainly French, influence was predominant, not only in the universities but in the Brazilian culture as a whole. World War II that ravaged all Europe substantially affected this supremacy, soon replaced by the influence of the United States of America. Besides the overwhelming role of the North American movies in diffusing the so-called "American way of life" that reached all social classes, the universities also eventually surrendered to the power of the US. One of the factors which contributed to this was undoubtedly the action developed by the Rockefeller Foundation in South America. The outbreak of World War II in 1939 caused a virtually complete arrest of research in the universities, and the grants sponsored by the Rockefeller Foundation were no longer needed. Thus, in the absence of research in Europe and in a number of Asian countries, the Rockefeller Foundation, which was already acting in Brazil, became more interested in the scientific development of South America, financing research works selected by its local representative, Dr. Harry Milton Miller Junior (1895-1971).

The role played by this Foundation was crucial at the time for ensuring the minimum of research then done here. It was not only by providing financial support for the local research, but also made it possible to send young researchers who had recently obtained their $\mathrm{PhD}$ in Brazil to the US for internships of one year or more at American universities. It is important to record that all this was achieved exclusively thanks to Dr. Miller's competent and experienced evaluation capacity. It should further be mentioned that all that was done without the need of a formal written research project. Not a single line! To obtain a scholarship for abroad it was indispensable, however, to undergo a medical examination performed by a Brazilian doctor trusted by the Foundation, besides laboratory tests. That was all. No report - whether partial or final - was requested! And, remarkably, the results were always excellent, without any record of failure.

This whole prodigality was accompanied by the adoption of a new model, the one used by the North-
American universities where the Brazilian researchers were sent to for their post-doctoral studies. There was a huge predominance of North American journals destined to the publication of scientific papers, whose editors were the ones who decided what should be published and what not. That was the rule. But it was also a way of them knowing, before anyone else, what was being done, and where in the world scientific work was being performed. It should, however, be very clear that the support given by the Rockefeller Foundation to the research conducted in Brazil, maintained over twenty years, was of vital importance for its road to self-sufficiency. Without this cooperation, this would probably not have happened.

The purpose of this article is merely to give a statement attempting to depict this movement of major transformation in the academic life of the Departamento de Biologia Geral at the FFCL-USP and, at the same time, to interpret the events of that period. In order to ensure maximum truthfulness, we hope to be able to duly acknowledge the efforts and dedication of those who worked in the Department, to clarify several mistakes and demystify things that were deceptive.

\section{The Multinational Megaprojects of $1948 / 49$ and 1955/56}

There is no doubt whatsoever that the great qualitative and quantitative leap in genetics in Brazil was due to the presence of two foreign professors in the State of São Paulo. In plant genetics and, consequently, in plant improvement, it was the presence of Professor Friederich Gustav Brieger (1900-1985) at the Escola Superior de Agricultura Luiz de Queiroz (ESALQ) in Piracicaba, already incorporated by USP at the time. With regard to general genetics, the issue is a bit more complex, deserving a more detailed explanation. Prof. André Dreyfus (18971952), one of the few Brazilians who earned the right, by means of a contest held in 1937, to occupy a chair in this early phase of setting-up of the Universidade de São Paulo, was surely the great responsible for the development of genetics, complemented, of course, by the presence in Brazil of Theodosius Dobzhansky (1900-1975) from Columbia University. When Dr. Harry Miller went to Dreyfus to offer his cooperation, he also suggested that Prof. Dobzhansky could spend some time teaching here, while Dreyfus was abroad, updating his knowledge and specializing in the US, as he wished. It was an offer. Dreyfus first refused, but was eventually persuaded to accept this suggestion and agreed to implement his initial proposal to bring to São Paulo an important researcher, probably from the field of genetics.

Dobzhansky had applied to the Rockefeller Foundation for a grant to work in Central America with tropical species of Drosophila (Diptera, Drosophilidae), but was willing to come to Brazil if the plan included, right at the start, a good period of time for him to get to know the Ama- 
zon region and collect specimens. Dr. Miller, who had already suggested Dobzhansky's name to come to Brazil, then became the middleman of this project.

As of that day, Dobzhansky discretely took over the command of the operations, and the initial project started to undergo modifications. His giving up the collection of specimens in Central America should be greatly compensated for, and Dobzhansky must have seen in the new project professional opportunities to his benefit. The request, or rather the condition imposed of visiting the Amazon region in exchange for coming to São Paulo, was only the beginning. There probably were some new proposals that were peacefully accepted by all the members of the group. Once the details were agreed upon, he scheduled his first visit for March 1943, but with a trip to the north of Brazil already organized and scheduled. Needless to say that he was outstandingly well received and every effort made to please him.

If this agreement was interesting for Dobzhansky, so it certainly was for the Chair of General Biology. Dobzhansky was going to see a good part of the Amazon region, the hard-to-fulfill dream of many naturalists and researchers. This opportunity was given to him. The Chair of General Biology, interested in having a full-time professor for one year, saw its plans changed by Prof. Dreyfus himself, who did not leave the country at that point, and also by Dobzhansky, who not only spent less time at the Department, but also did not take over the teaching of any curricular course. He very successfully held a series of highly disputed lectures on the Theory of Evolution, a synthesis of the second edition of his famous book Genetics and the Origin of Species, published in 1941. He also made several excursions to collect Drosophila specimens and got to know a number of places in Brazil. Actually, all these trips were part of a plan to investigate the natural conditions here in Brazil, in order to work out a megaproject that, in fact, was made and successfully implemented, thanks to Dobzhansky's prestige and, why not say it, his intellectual ambition. Should you ask what the Departamento de Biologia Geral gained with it, there cannot be any doubt that it was a lot. Dobzhansky paid a fair price for getting what he wanted. Actually, he adopted the Departamento de Biologia Geral as an extension of his own laboratory. His presence in the Department must have been of great help in obtaining grants from the Rockefeller Foundation for the research he was conducting, the projects of his utmost scientific interest. They would be the proof or extension of his hypotheses, already tested on the northern hemisphere, in regions with temperate climate, needing to be corroborated in regions with tropical climate.

This was the goal, this was his wish, his need and his will. He would not refrain from providing a research project to one of these new collaborators. He was sure that all data obtained would immediately be handed over to him, thus giving him the option of writing the paper himself or simply reviewing and correcting the manuscript of the colleague who had done the work, which left him in absolute control of the results. It should be reminded that Dobzhansky was at the time a very successful researcher, who had become famous and respected in the whole scientific world. He worked with some professionals of the highest scientific level, such as the eminent geneticist Sewall Wright (18891988), which conferred him an even greater credibility. He was the one who, along with John Burdon Sanderson Haldane (1892-1964) and Ronald Aylmer Fisher (1890-1962) launched, in the early 1930's, the theoretical grounds of population genetics and provided the models for population analyses. He was, therefore, a powerful consultant to most scientific journals, starting with the Proceedings of the National Academy of Sciences, the famous PNAS, itself, since he was also a member of the American Academy of Science.

When we had already finished writing this article, we were informed by Professor João Stenghel Morgante about the comments made in an interview by Richard Charles Lewontin, a former student of Dobzhansky's, published in volume II of the book Thinking about Evolution - Historical, Philosophical, and Political Perspectives, of 2001. There, in the section "Life in Dobzhansky's Laboratory and Dobzhansky's Problematic", he attributes to Dobzhansky's known charisma the prestige earned among researchers all over the world, and much of what he tells there is so similar to what we had written that we transcribe here a segment of his interview, so the reader can judge for him(her)self.

"That is to say, by his driving personality, Dobzhansky would essentially tell each person what experiment really needed to be done. The person might or might not participate in the experiment, but usually Dobzhansky planned the experiment, picked out the files to be used sometimes in consultation with Howard Levene, who was his statistical adviser - and then the person did the experiment. The data were then brought to Dobzhansky, and he analyzed them or had Howard analyze them. Then Dobzhansky wrote the paper, and it was published under the name of the person who had done the physical work, with or without Dobzhansky's name as a coauthor."

Although Dobzhansky's coming to São Paulo was extremely beneficial, it had unfavorable consequences. This was brought about by the fact that, despite his familiarity with genetics, he was not exactly what is commonly called a classical geneticist, such as Morgan or Sturtevant. He was a Darwinian evolutionist who had realized, better than anyone, the scientific potential of using the basic knowledge of population genetics in studies on the Theory of Evolution. In fact, he was virtually a pioneer in this line of research and became a role model for many researchers all over the world.

We believe that the development of Genetics in our country could have been much greater and more consistent if the basis of Classical Genetics had been developed to- 
gether with Population Biology. As can very well be observed at present, the promising future was in developing Classical Genetics, in the fields which led to gene studies and eventually disclosed their chemical nature and the genetic code. At that time, the late 1950's, some Brazilian geneticists were taken by despair because of the huge gap of knowledge between us and the researchers abroad. This gap was only bridged many years later. Population studies lost part of their charm after providing the results needed. Science has its trends, because it is highly dynamic and progresses fast, leaving behind a beautiful and important history, full of heroes. Who does not revere, to our days, people like Mendel or Morgan?

Dobzhansky's coming to Brazil did not contribute at all to the creation of research in the field of classical genetics, i.e., basic genetics. This is no criticism, but a mere statement. He had no such commitment or obligation. Maybe the only one to blame was the Department, for not attempting to complement his research plans and encouraging the implantation of other fields, which should have been developed. Yet he did contribute, in a very intense and successful manner, to the research that could nowadays be called Population Biology, or simply the application of population genetics in experiments with natural populations, with the main purpose of revealing, clearer and more precisely, the evolutionary process that leads to the formation of new species.

Dobzhansky visited Brazil and was fascinated by the potential of developing here research to complement his work. He gave a major contribution to the knowledge of the systematics of Drosophila species and to the formation of new researchers. He was also charmed by the receptivity of the Brazilian society, ever so keen on excessively pleasing foreign visitors. However, in the book published by Bentley Glass containing part of his correspondence (Dobzhansky, 1980), he not only pointed out this receptivity shown by several Brazilian authorities who granted him huge operational favors to allow him to achieve his objectives, but showed a certain ungratefulness by severely criticizing Brazil and our costumes at the time. He even ridiculed the contest for a chair at USP, whose protocols were certainly based on models from West Europe.

Given this highly favorable situation, it must not have been difficult for Dobzhansky to conceive a research project of much larger and more ambitious proportions. He intended to perform experiments throughout South America, targeting a diversity of biomes, different from those which existed on the northern hemisphere, in order to test the scope of his theories based on results obtained in his studies conducted in the US. To this end, he did not hesitate to prepare a situation that would naturally lead to his goal.

The great majority of natural Drosophila species populations are apparently uniform, characterizing what is called the wild type. However, these populations comprise a huge genetic variability that is not expressed pheno- typically, but can only be evidenced by analyzing lineages especially prepared for this purpose. Dobzhansky had to establish lineages of species living in the same region he was going to work in, just as he had done with the North American species. Those were rather complex lineages, named balanced lethals, produced in the laboratory by introducing into a given pair of chromosomes, intended to be the object of a population analysis, dominant mutant alleles (morphological markers) and lethal alleles within paracentric chromosomal inversions which make the products resulting from crossing-over within the inversion unviable. They allow, by means of a number of crosses, to achieve homozygosis of a given chromosome extracted from the natural population, and thereby to identify its genetic constitution regarding the presence of lethal, semi-lethal and sterile alleles. Actually, for this purpose two lineages are necessary for each chromosome.

The first lineage of this kind, used to detect lethal mutations in the X-chromosome, was originally produced in Drosophila melanogaster by Herman Joseph Muller (1890-1967) in 1928 and named $C l B$. In the females of this lineage, one of the $\mathrm{X}$-chromosomes contains a large paracentric inversion (factor $C$ ), into which are inserted, among others, one recessive lethal allele $(l)$ and one mutant dominant allele of the Bar gene (between which crossing-over may occur, which however result in unviable gametes), constituting a phenotypic marker, once the female with the altered allele (actually a duplication of the gene) has kidney-shaped eyes, different from the elliptical eyes of the wild female.

After collecting Drosophila specimens in several parts of Brazil, analyzing them and identifying the species, their frequencies of occurrence and the extension of their geographic distributions, Dobzhansky chose two widely distributed species to be used in his future experiments. One of them, D. prosaltans, had a low frequency in the samples, while the other one, $D$. willistoni, had a high frequency.

Dobzhansky took several samples of these two species to his laboratory at Columbia University and had one of his technicians, the Russian Boris Spassky, develop lethal-balanced lineages, as had been done with the North American species D. pseudoobscura. Four lineages were established for each one of the species, two for chromosome II, and the other two for chromosome III mutant analysis. It was a work of pure basic genetics, hard and timeconsuming, that took over four years to be completed.

Once having these lineages, Dobzhansky was ready to get his plan started. That was when he presented his first megaproject to the Rockefeller Foundation: to conduct a research using in part of it the lethal-balanced $D$. willistoni and $D$. prosaltans lineages in Brazil, and to bring together in São Paulo, at André Dreyfus's chair, researchers from other Brazilian states and even from other countries. Worth mentioning is the fact that the title of Prof. Pavan's habilita- 
tion ["livre-docência"] thesis used these D. willistoni lineages, and Prof. Cavalcanti, from Rio de Janeiro, used the D. prosaltans lineages for his full professor thesis.

Dobzhansky's megaproject was planned to be carried out from August 1948 to July 1949. Other participants of this group, in addition to the members of the Departamento de Biologia Geral [André Dreyfus, Crodowaldo Pavan (1919-2009) and Antônio Brito da Cunha (1925-)], were: Hans Burla (1920-2010) from Zurich, Antônio Rodrigues Cordeiro (1923-) from the Universidade Federal do Rio Grande do Sul, Antônio Geraldo Lagden Cavalcanti and Chana Malogolowkin (1925-) from the Universidade Federal do Rio de Janeiro, and Marta Wedel from Buenos Aires (Figure 1). Oswaldo Frota-Pessoa (1917-2010) from Rio de Janeiro had sporadic contacts with the group, but
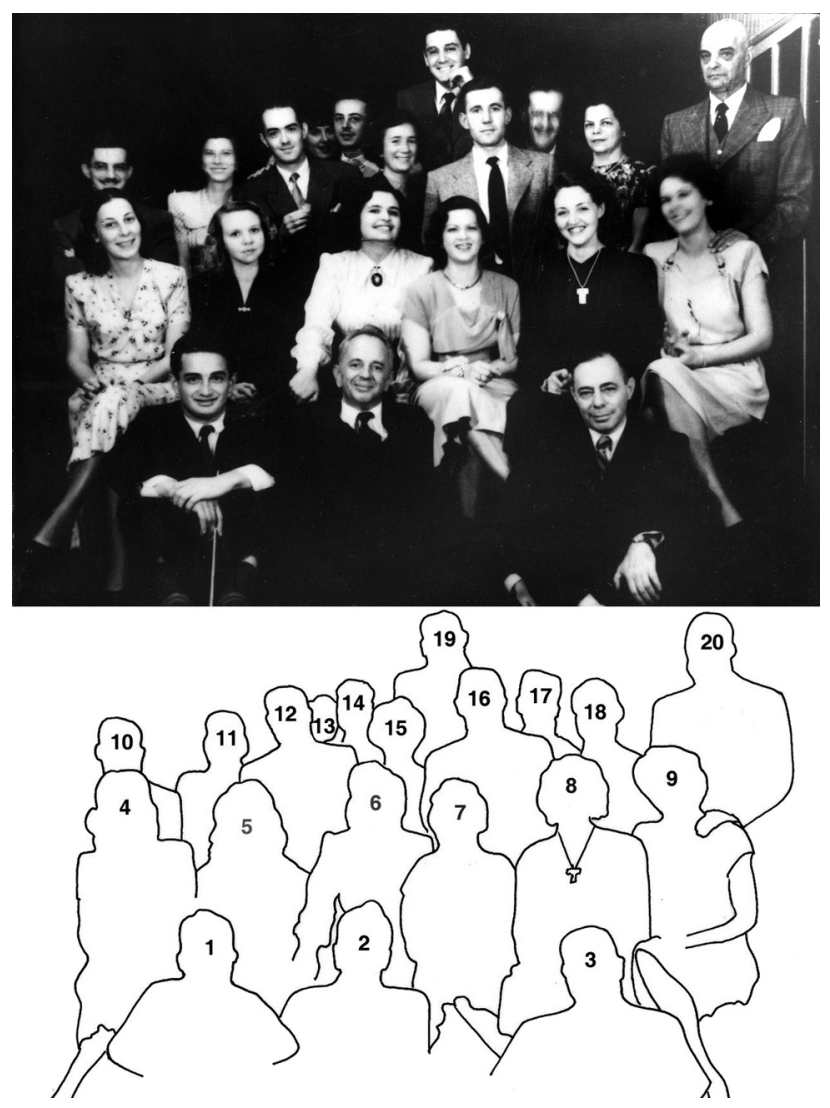

Figure 1 - Probable farewell party for Prof. Theodosius Dobzhansky, in the first half-year of 1949, at the Departamento de Biologia Geral of FFCL-USP, then located in the attic of the Jorge Street Mansion, at Alameda Glette 463, Campos Elíseos, São Paulo, SP. (From the archives of the Memory Committee of the Departamento de Genética e Biologia Evolutiva of the IB-USP) (Observation: this image was previously released for illustrating an interview by Marco Antonio Coelho with Professors Crodowaldo Pavan, Antonio Brito da Cunha and Erasmo Garcia Mendes, published in 1993 in Estudos Avançados 7:189-207). 1. Crodowaldo Pavan, 2. Theodosius Grigorievich Dobzhansky, 3. André Dreyfus, 4. Marta Wedel, 5. Ruth Ferri, 6. Maria de Lourdes de Oliveira Pavan, 7. Inah Cavalcanti, 8. Malvina Cordeiro, 9. Chana Malogolowkin, 10. Mário Guimarães Ferri, 11. Lígia Brito da Cunha, 12. Antônio Brito da Cunha, 13. Flávia Naves Freire Maia, 14. Newton Freire Maia, 15. Anita Nickele, 16. Hans Burla, 17. Antônio Geraldo Lagden Cavalcanti, 18. Cândida de Paula Souza, 19. Antônio Rodrigues Cordeiro, 20. Otávio Vaz de Oliveira. studied Drosophila systematics on his own. Warwick Kerr (1922-), a geneticist who achieved his specialization in Piracicaba, under the advisement of Prof. Brieger, also kept in touch with the São Paulo group. At that time, there was someone else working in the Departamento de Biologia Geral, a young man coming from Minas Gerais, graduated in Dentistry, who came to the building located at Alameda Glette carrying a small book on Genetics written by himself. He convinced Prof. Dreyfus to hire him as a teaching assistant ["Auxiliar de Ensino"]. That young man was Newton Freire-Maia (1918-2003), who had not been included in Dobzhansky's group. Sometime later, around 1952, he moved to Curitiba, where he worked until his retirement at the Universidade Federal do Paraná. There, besides continuing his work with Drosophila species, he started an important line of research on human consanguinity. He, together with Frota-Pessoa and Pedro Henrique Saldanha and with the support of the Rockefeller Foundation, mediated by Pavan, were the great mentors of Human Genetics in Brazil, followed a little later by Francisco Mauro Salzano from Rio Grande do Sul.

The scientific production of the three following years (1949 to 1951) amounted to thirty published papers (Supplementary Material, Table S1), with the participation of nineteen authors, only seven of which were members of the Departamento de Biologia Geral. Pavan was the author or coauthor of eleven papers, Dobzhansky of ten, and Antonio Brito da Cunha of nine. In addition to these authors, others from Rio de Janeiro and Rio Grande do Sul, from the US, Switzerland and Chile participated in these publications. Fifteen papers had a single author, six had two, and seven had three. Then there was one paper each with five, one with six and one with seven authors, respectively.

One of the main products of this megaproject was the setting-up of scientific research in a field of great interest at that time, which meant performing cutting-edge research, of international level, that circulated in the best specialized journals. With this strategy, Dobzhansky obtained privileges not only for the Departamento de Biologia Geral of the FFCL-USP, but - maybe to a lesser degree - also for the Federal Universities of Rio de Janeiro and Rio Grande do Sul. Professors of these three universities made internships with Dobzhansky in his laboratory at Columbia University. Undoubtedly the achievement of this project was a major accomplishment, and these three universities experienced a significant development, reflected by their relevant scientific contributions to the fields of Theory of Evolution, Systematics and Population Biology.

Even after concluding the practical activities of the 1948/1949 megaproject, the relationship among its participants continued by mail, in order to finish the manuscripts of the works that began to be published. Moreover, there were also exchanges on a more personal level, such as agreements concerning internships in the US. The excellence of the results encouraged the Rockefeller Foundation 
to accept new requests and to finance new projects. It should be remembered that, at that time, the research projects did not have to meet the evaluation criteria that the funding agencies currently impose onto their candidates. Practically, Dr. Miller's intuition was the supreme judge who decided who should or should not be recommended to the Foundation's Superior Council for approval of the request. As he was the one traveling around and keeping in touch with the candidates for grants, his opinion was certainly highly valued. The projects which were approved and successfully carried out were very likely to continue receiving support. The professionalization of Brazilian science is highly indebted to the Rockefeller Foundation and, without any doubt, to Prof. Miller.

Brazilian genetics was one of these privileged fields. Good projects, carried out with seriousness, publications in prestigious scientific journals, besides the presence of Prof. Dobzhansky on the peak of his fame, guaranteed approval. Moreover, it was evident that the integrated work of researchers from several institutions was an efficient multiplying factor of good results, besides being more costeffective, as they consumed fewer resources than if each one of them was to receive support individually. Thus it was a good investment, and the Foundation should hope for them to go on requesting grants, in order to have clients with guaranteed success.

That was the context in which Dobzhansky and Pavan decided to try and conduct a second megaproject. Dobzhansky had a theory on his mind and wished to prove it. At that time, population studies attempted to evaluate and understand the genetic diversity of natural populations, mainly of species of Drosophila. There were two models attempting to explain their maintenance, each one defended by a different school or current, which sustained a fierce battle based on data, evaluations and mathematical models. One of them can be called a mutational model and the other, a heterotic model.

The latter hypothesis was defended by Dobzhansky and several other geneticists. Dobzhansky had been thinking about some experiments which might bring more information to support the model. To this end, he invited Pavan to take part in a common new megaproject, involving of course Brazilian researchers and also from institutions in other countries. This project demanded a lot of money, but the Rockefeller Foundation did not refuse to provide it.

Upon one of his visits to Brazil, flying from Rio de Janeiro to São Paulo, Dobzhansky saw, as he overflew Angra dos Reis, countless islands which would suit perfectly the experimental model he wanted to test. As he said himself, "they are true natural population boxes". Population boxes were a kind of equipment used to study in the laboratory, under controlled conditions, a number of genetic issues in Drosophila populations with a known initial genetic composition. They allowed sampling the populations to analyze them quantitatively and see what alterations had occurred.
Carried out in nature, the experiment would be closer to reality, with the populations being subjected to all sorts of environmental factors, but limited by the size of the island, allowing a quite representative sampling.

Dobzhansky and Pavan then started their plans to conduct the large scientific experiment in Brazil. They considered bringing Louis Charles Birch (1918-2009), an Australian researcher who had obtained his $\mathrm{PhD}$ in England and had just published, with Herbert George Andrewartha (1907-1992), a very successful book, The distribution and abundance of animals, presenting theories about the size of populations and a comprehensive review of the literature. It was a major happening. Birch was invited to participate in the team, and his acceptance caused great satisfaction, for his name was quite prominent in the world of science at that time. Two further researchers were invited, one a young geneticist from Padua, Bruno Battaglia (1923-2011), who specialized in maritime crustaceans (copepods), who came with his wife, Laura. The other one was a Danish researcher who had recently obtained his $\mathrm{PhD}$, Ove Frydenberg (1928-1975), who also brought along his wife, Inger. The fellowship for Ove Frydenberg was not granted by the Rockefeller Foundation but by the USP Rector's Office, obtained thanks to Prof. Pavan, maybe as a reciprocative gesture of the University. Fair enough, considering that these international research programs gave good visibility to the University. Pavan then decided to include some Brazilians in the group. Two women were chosen, Cora de Moura Pedreira (1915-2005), a physician who was doing research in human genetics in the state of Bahia, and a fresh graduate in Biology, Myrthes da Silveira Nilo Bispo, from the state of Pernambuco. And then there were the members of the Departamento de Biologia Geral itself, of which practically all took part in the project: Pavan, Brito da Cunha, Elisa Pereira Knapp (1923-2010) and Luiz Edmundo de Magalhães (1927-2012; Figure 2). The project (Figure 3) started between June and July 1955.

Since Prof. Magalhães' wife was of Danish origin, Pavan thought it would be nice if the couple could go to Santos and wait for the Frydenbergs at the port, since they were coming by ship. As Frydenberg's fellowship was the lowest of all and he was going to have extra expenses because his wife was late in pregnancy, the Magalhães invited the two to stay with them at their home, which made them very close and gave rise to a great friendship between the two families.

The group was very excited and full of hope regarding the great research project. Once everybody had arrived in São Paulo, an excursion to Angra dos Reis was scheduled, to give all the opportunity of getting to know the islands where the experiments would be carried out. Pavan and Dobzhansky held a meeting with the most representative members of the group, to expose the project and discuss its execution. That was where the problems started. Dobzhansky exposed the project that he had conceived 


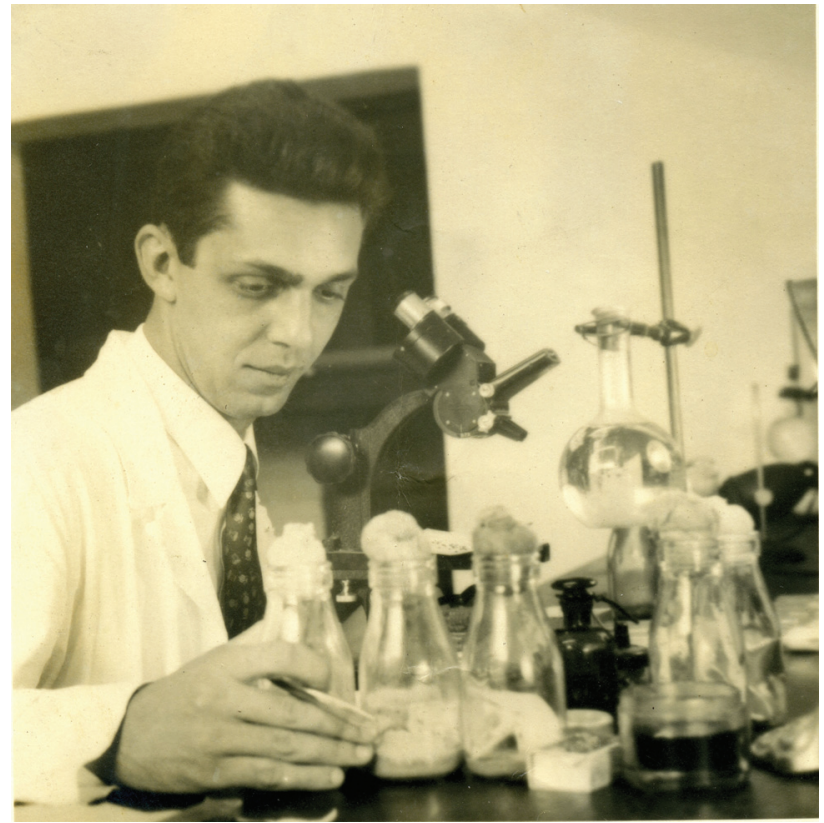

Figure 2 - Luiz Edmundo de Magalhães in his laboratory in the basement of the Jorge Street Mansion, in 1955 (archives of the first author).

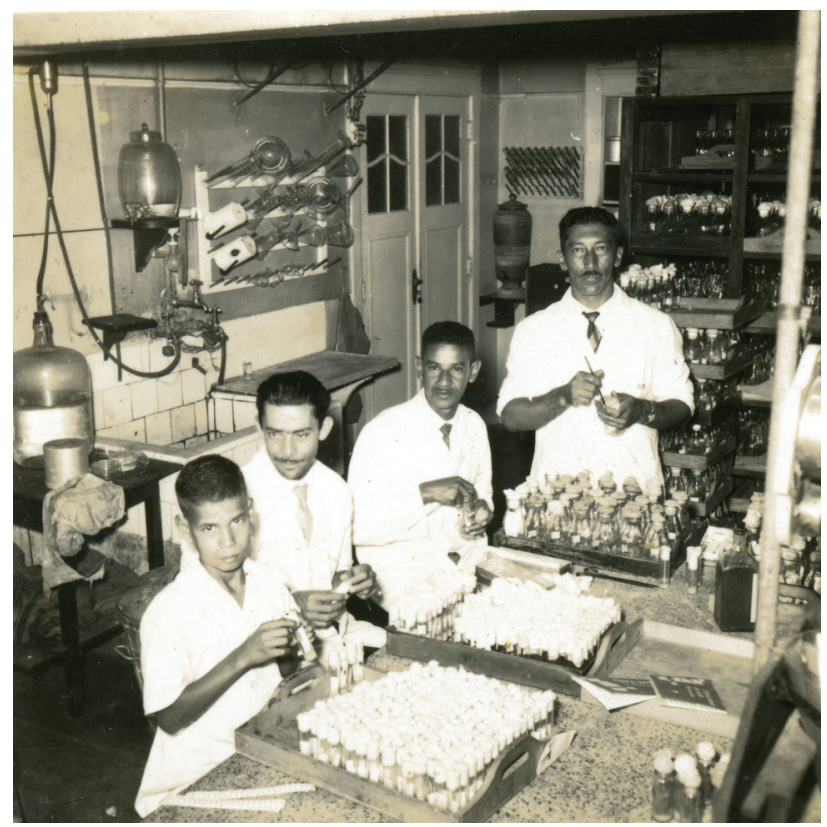

Figure 3 - Laboratory where culture medium was prepared at the Department of General Biology of the FFCL-USP, probably in 1956. Left wing of the attic of the Jorge Street Mansion. From left to right: the laboratory technicians Rubens Monteiro, Ramiro Gomes, Pedro Monteiro and Gabriel do Prado Bueno (archives of the Memory Committee of the Departamento de Genética e Biologia Evolutiva of the IB-USP; donation by GPB).

himself, but, to his great surprise and displeasure, the fresh PhD Ove Frydenberg, the youngest in that group, presented severe criticisms, contesting its viability. The project did not test the intended hypotheses. It was statistically inconsistent, so there was no justification whatsoever to perform an experiment known, from the beginning, to be impossible to work out. Frydenberg was a brilliant young man and had a good background in the fields of statistics and philosophy of science. He was brave, coherent and consistent. However, Dobzhansky did not give in to his arguments. He answered that, in his opinion, there were only two kinds of science: the innovative and the non-innovative. The project in question was innovative, ergo a good project, and therefore it should be carried out. The Dane found himself alone, for nobody dared upsetting the "old man", as he was already being discretely called in small groups. The meeting finished badly. Frydenberg was excluded from the team, but kept his fellowship from the University and developed several other projects on his own. That gave rise to a true hatred of Dobzhansky with regard to the young man. And, since Ove was a guest in the Magalhães home, this same hatred was extended to this family.

Luiz Edmundo was working with Pavan in experiments to measure the flight radius of $D$. willistoni. The work consisted in using flies from the laboratory stock, label them with histological stain impregnated in wheat flour, count them and release them in the experimental field. After a given period of time, collections were made on baits placed at known distances and distributed in a cross-shaped manner. The data obtained by this method allowed estimating the flight radius, the size of the population and, according to the study design, measuring the birth and mortality rates. This was the subject matter Pavan had chosen for Luiz Edmundo's doctoral thesis. In order to obtain better knowledge of the subject, they got in touch with Professor Wilfred Leslie Stevens (1911-1958), from the Departamento de Estatística (Statistics Department) of the Faculdade de Economia e Administração (School of Economy and Administration) of the USP, a famous researcher who had been one of Prof. Fisher's students in England. He was considered one of the highest IQs of that country and was therefore appointed to work for the British Secret Service in Portugal during World War II. Afterwards he came to Brazil. Stevens had perfect knowledge of the literature concerning studies which estimated the size of natural populations and was enthusiastic about the problem presented to him. He joined the group and took part in the experimental planning, as well as in virtually all excursions to Pirassununga, where the experiments were carried out. Unfortunately Prof. Stevens died suddenly during our work, which represented a huge loss to science in the fields of statistics, mathematics and genetics.

Luiz Edmundo also took part in all excursions to Angra dos Reis, to help collecting the material. The episode regarding the disagreement between Dobzhansky and Frydenberg had receded somewhat, but Dobzhansky was still very upset by Ove's presence, whom he did not even greet. Ove, in turn, dealt with irony with the situation, performing dramatized reverences whenever they ran into each other by chance. He was sure that this would upset 
even more the "old devil", as he was called then secretly in English by most of the members of the group.

In spite of the relationship issues, work was progressing well but did not last long. One morning, Pavan approached Luiz Edmundo and went straight to the point, saying: - "Look, Dobzhansky wants you to stop working in Pirassununga and go prepare your doctoral work in Angra dos Reis. Check if there is any migration of flies among the islands and determine the size of the local populations. He said that, if you don't agree with this, he will abandon the program and go back to the US, and write to all his friends saying that it is not possible to do scientific work in Brazil. If this happens, we will be unable to obtain any financial support. It's your call what to do." And he walked away without as much as giving him a chance to say anything about this absurd behavior. Obviously this change of plans was not an easy thing to accept, but Luiz Edmundo would rather agree and see what would happen. He could not let the responsibility for such a damage, unfair to the whole Departamento de Biologia Geral, rest on his shoulders. What interest could Dobzhansky have in the young Luiz Edmundo and his work? What difference would it make if he worked in Angra or in Pirassununga? Actually, the real reasons of the "old man's" move would become clear to us only later on.

The project designed by Dobzhansky consisted basically of choosing a number of genetic markers, such as lethal alleles and chromosome inversions, some originated in the local population itself and others coming from natural populations of different regions, introducing each marker in one island in great amounts and observing how they behaved over time. The main islands chosen were São João, Queimada Pequena, Queimada Grande, Porcos Pequena, Porcos Grande, Cavaco and Duas Irmãs (Figure 4). From time to time, samples were collected and analyzed. Concomitantly, marked flies were released into nature, in order to estimate the size of the populations and verify whether there was occurrence of migration or not.

Suddenly, in certain samples, markers started to appear, i.e., certain inversions which did not exist in these populations nor had they been introduced, were found at high frequencies. Dobzhansky immediately drew his conclusions: - "Frydenberg and Magalhães are sabotaging the experiments so they won't succeed!". This made everybody feel very bad. The lineages used by Luiz Edmundo for estimating population sizes, duly authorized to be released on the islands, had all been previously analyzed. There was no possibility of any sabotage having occurred. Brito da Cunha took it upon himself to re-evaluate the lineages and never found any sign of contamination of the cultures used to measure the population size. The possible and almost inevitable explanation was that actually Frydenberg was right. When Dobzhansky realized that and came to his senses, he made another absurd demand, obliging Magalhães to change his work field and go release flies from the

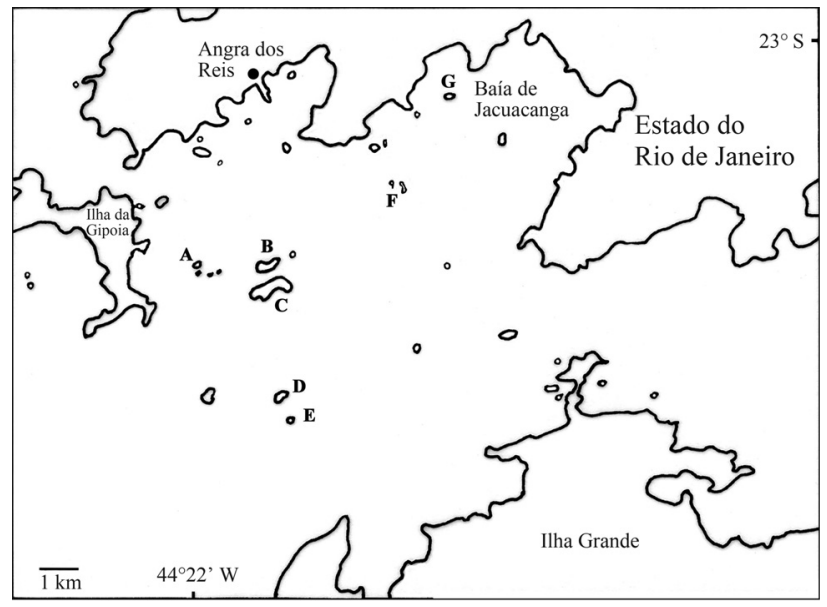

Figure 4 - Localization of the islands near the port of Angra dos Reis where, from 1955 to 1956, the Drosophila willistoni release and capture experiments were carried out: A) São João island; B) Porcos Pequena island; C) Porcos Grande island; D) Queimada Grande island; E) Queimada Pequena island; F) Duas Irmãs islands; G) Cavaco island. Redrawn from the nautical map 1636 of the Head Office of Hydrography and Navigation (Brazil. 2004. Port of Angra dos Reis and surroundings, $3^{\text {rd }}$ ed., Rio de Janeiro, Brazilian Navy).

laboratory at Angra dos Reis. This would, if necessary, give him a possibility to justify the results by blaming sabotage for what was happening.

The atmosphere became unbearable and the group (Figure 5) eventually dispersed. Brito da Cunha, however, proceeded with his analyses and, later on, he accidentally found in a drawer of the work table where the photomicroscope used by Dobzhansky stood, a notebook with his notes on the analyses of the first samples from the islands, used to decide which markers were to be used. And he found, recorded by Dobzhansky himself, the presence of a genetic marker, an inversion of the $D$. willistoni chromosome II, common in samples from Belém do Pará. Dobzhansky had disparaged this finding when he started the experiment, considering this marker to be absent in the island populations. This is the actual explanation: the marker already existed in the population of one of the islands, so its presence in the samples needed no explanation, for it was already there. It is regrettable that a group of so highly qualified researchers, of great scientific relevance, had to go down such a suspicious path, supported by vanities and prides.

An interesting fact to be pointed out here is that an experiment similar to the one designed for Angra was performed in Rio Grande do Sul by A. R. Cordeiro, Francisco Mauro Salzano (1928-) and Vera Bandeira Marques. Instead of islands, the research was conducted in small groves named capões. Sixty thousand hybrids of northern and southern D. willistoni "races" were released in three groves in the Tainhas region. The results of this experiment are the only ones published (Cordeiro et al., 1960). 


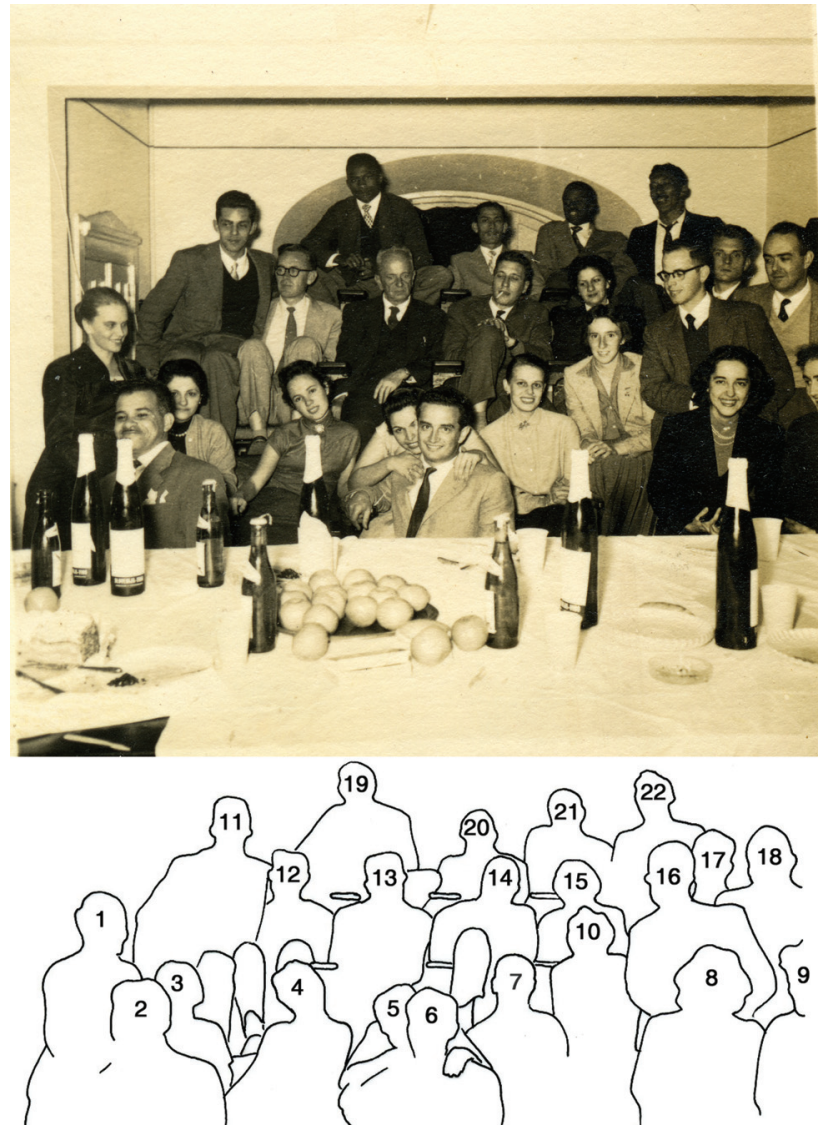

Figure 5 - Farewell party for Prof. Theodosius Dobzhansky, in July 1956, in the classroom for theoretical classes of the Departamento de Biologia Geral at the FFCL-USP, located in the right wing of the attic of the Jorge Street Mansion (archives of the first author). 1. Inger Frydenberg, 2. Henrique Serafim de Oliveira, 3. Cora de Moura Pedreira, 4. Myrthes da Silveira Nilo Bispo, 5. Maria de Lourdes Vaz de Oliveira Pavan, 6. Crodowaldo Pavan, 7. Nícia Dulce Wendel Magalhães, 8. Jeanete Saraiva de Toledo, 9. Natalia Gabrusewycs, 10. Hebe Mirina Laghi de Souza, 11. Luiz Edmundo de Magalhães, 12. Louis Charles Birch, 13. Theodosius Grigorievich Dobzhansky, 14. Bruno Battaglia, 15. Therezinha de Moraes Ungaretti, 16. Willy Beçak, 17. Ove Frydenberg, 18. Antonio Brito da Cunha, 19. Geraldo Barnabé, 20. Pedro Monteiro, 21. Waldemar de Oliveira, 22. Gabriel do Prado Bueno.

\section{Conclusions}

Although the facts leading to the end of the Angra projects with Dobzhansky caused major commotion in all the participants, especially because of their unusual nature, there never seems to have been any explanation by the persons responsible for the project. It was a sad end, just like something fading in the air. On the other hand, however, it seems to have represented the coming of age of the Departamento de Biologia Geral. It was the end of the Dobzhansky Era. Thus, the responsibility for the fate of the Department was left exclusively in the hands of its own members. Work went on, and the Rockefeller Foundation still funded their research until 1960, when they decided no longer to invest in South America.
It is interesting to record that Luiz Edmundo de Magalhães concluded his doctoral work with the research made at Angra and was soon after, in 1959, granted a fellowship from the Rockefeller Foundation, approved by Prof. Miller. Pavan was the one who chose the laboratory for his internship. He was accepted by the University of Texas at Austin, where he worked with Prof. Marshall R. Wheeler (1917-2010) at the Genetics Foundation. He stayed there from March 1959 until June 1960, and the last four months were an extension of his fellowship, requested by the institution. Actually, they wanted to have him hired for a longer period of time by the University. During that time, he published three papers.

When he was already more familiar with the local group, in a casual chat with some professors, Dobzhansky and his behavior were mentioned. At that point, Professor Wilson Stuart Stone (1907-1968), president of the Genetics Foundation, told him that he had received a letter from Dobzhansky recommending him not to accept Magalhães for the internship. That was enough, he said, to consider him a good candidate and accept him. A general laughter followed.

Dobzhansky's reputation was actually far from good. In 1959, while in Texas, Magalhães took the occasion to attend the famous annual symposia at Cold Spring Harbor, Long Island. There he met and got to talk with several scientists who disliked Dobzhansky. Right then his laboratory was undergoing a serious crisis because he had had a falling-out with his two main assistants, Mr. and Mrs. Spassky, who took care of everything in the laboratory.

That was a time when the Departamento de Biologia Geral, as well as the entire Universidade de São Paulo and the local society, were going through major transformations and experienced a significant growth. The number of students increased from one year to another. The Department was preparing to move to the new campus, the Cidade Universitária, which happened in mid-1959. The number of faculty also started to increase, so as to meet the new needs.

Pavan was intensely involved with a new project: cytological studies of larvae of the fly then called Rhynchosciara angelae that had been described by himself and Edmundo Ferraz Nonato in 1951. This research increasingly consumed his time and attention. His main assistant with these studies was Marta Erps Breuer, a person of difficult personality but a competent technician with several skills, especially drawing.

A major problem came to foster the survival of the population biology studies that had already started to present signs of being on a declining path. It was the publication of an article by Muller (1950) entitled "Our load of mutation" that drew attention to the severe effects of using nuclear bombs, a strongly mutagenic agent that, according to the article, could put at risk the very survival of the human species. This triggered worldwide a number of national and international policies. 
The main genetics centers dealing with mutations and population phenomena were recruited to supply experimental data for rigorously evaluating the true risks for life on Earth. Pavan represented Brazil at the UN Scientific Committee on the Effects of Atomic Radiation and Nuclear Weapons and took the initiative of conducting a number of projects related to the matter, with funding from the Brazilian National Committee for Nuclear Energy (CNEN). The subject of his research was a comparison between the survival of natural lethal recessive alleles and those induced by radiation. These experiments, performed with Drosophila willistoni, were also conducted on the islands at Angra dos Reis. When Magalhães analyzed, after a few generations, the data on the frequencies of the lethal alleles introduced on the islands, he observed that they oscillated over time from one sample to another, i.e., they were sometimes higher and sometimes lower. As different methods were used in these analyses to identify the introduced lethals, the frequency variation was found to be related to the method of analysis employed. One of these was the classical lethal isolation method, in which two lethal-balanced lineages were used, one named "Emarginata" and the other, "207". With the obtained lethals, allellism tests were done to find out which of them corresponded to the offspring of those introduced on the islands. The other method was a simplification, in which the lethal was not actually isolated from the analyzed sample. The allelism test was made directly from the males of generation $\mathrm{F}_{1}$ of the cross between Emarginata females and the collected males. To save time, these methods were used by alternating the analyses of the collected samples. One of them resulted in a lower allelism frequency, and the other, in a higher one. So Magalhães tried to find an explanation for these results and observed that two things might be occurring: one being the formation of synthetic lethals, an idea that was very in style at the time, and the alternative one, the occurrence of crossing-over in the crosses made in one of the analyses, meaning the nonfunctioning of the lethal-balanced lineages used in the laboratory (de Magalhães et al., 1965a,b). Later on, Professor Brito da Cunha confirmed the occurrence of crossing-over in the lineages used. The results of his research were published by França and da Cunha (1968) and França et al. (1968). This whole episode is told by da Cunha (1998), in a way that does not quite coincide with what we know about the facts.

Soon after the experiments at Angra were finished, Pavan accepted an invitation to run a laboratory at Oak Ridge, Tennessee. Afterwards he was invited to occupy the position of a Full Professor at the University of Texas at Austin, and lived for many years far from Brazil.

In time, new faculty members were hired and new research areas were set up. In addition to the already mentioned studies of the polytene chromosomes of larvae of Rhynchosciara angelae (that later on [1969] would be considered by Marta Erps Breuer (1902-1975) a junior syn- onym of R. americana) and other insects, a new group was also constituted to study the true fruit flies (Tephritidae). Oswaldo Frota-Pessoa, who was already faculty at the Department and was working in human genetics, started to develop the medical part of genetic counseling. All this led to a reduction in the studies on Drosophila species. New times were coming.

Table S1 lists all the scientific articles on Drosophila species published along 17 years (1943 to 1959) by researchers who were directly or indirectly trained by Theodosius Dobzhansky at the Departamento de Biologia Geral of the FFCL-USP, with the support of the Rockefeller Foundation. Currently (in 2012), the Laboratory of Drosophilids of the IB-USP, a remainder of the "golden years", is still fully active, but with only two still working and one retired faculty, Carlos Ribeiro Vilela (1949-) and Lyria Mori (1946 -) and Francisca Carolina do Val (1945-). They do research in ecology, systematics and evolutionary biology of neotropical Drosophila species, in addition to teaching basic genetics, where they use for the practical classes only specimens of Drosophila melanogaster, the unmatched model organism that was established by the school of Thomas Hunt Morgan at Columbia University. University outreach activities consist of identifying Drosophilidae species on request from researchers from Brazil and abroad and especially of giving teaching directions and providing samples of a great variety of mutant Drosophila melanogaster lineages to local and foreign high school and college teachers.

\section{Acknowledgments}

The authors are very grateful to professors Francisco M. Salzano, Ângela M. Vianna-Morgante, João S. Morgante and Fábio de Melo Sene for critical reading of the early versions of the manuscript and suggestions given; to Suzana Casaccia Vaz for the tip regarding the nautical maps for the localization of the islands in the Angra dos Reis region, to Nicia and Marina Wendel de Magalhães for their help with typing and revising the text, and to Nicole Grosso for translating the original Portuguese manuscript into English.

\section{References}

Cordeiro AR, Salzano FM and Marques VB (1960) An interracial hybridisation experiment in natural populations of Drosophila willistoni. Heredity 15:35-45.

da Cunha AB (1998) On Dobzhansky and His Evolution. Biol Philos 13:289-300.

Dobzhansky TG (1980) The roving naturalist: Travel letters of Theodosius Dobzhansky. Mem Am Philos Soc 139:1-327.

França ZM and da Cunha AB (1968) Crossing-over between heterozygous inversions and its relation with polymorphisms of Drosophila willistoni. Rev Bras Biol 28:495-497.

França ZM, da Cunha AB and Garrido MC (1968) Recombination on Drosophila willistoni. Heredity 23:199-204.

Lewontin RC, Paul D, Beatty J and Krimbas CB (2001) Interview of R.C. Lewontin. In: Singh RM, Krimbas CB, Paul DB and 
Beatty J (eds) Thinking About Evolution: Historical Philosophical and Political Perspectives, vol II. Cambridge University Press, Cambridge, pp 22-61.

de Magalhães LE, da Cunha AB, de Toledo JS, Toledo Filho S de A, de Souza HL, Targa HJ, Setzer V and Pavan C (1965a) On lethals and their suppressors in experimental populations of Drosophila willistoni. Mutat Res 2:45-54.

de Magalhães LE, de Toledo JS and da Cunha AB (1965b) The nature of lethals in Drosophila willistoni. Genetics 52:599608 .

Muller HJ (1950) Our load of mutation. Am J Hum Genet 2:111$-176$.

\section{Supplementary Material}

The following online material is available for this article:

Table S1: Scientific articles published along 17 years.

This material is available as part of the online article from http://www.scielo.br/gmb.

Senior Editor: Fábio de Melo Sene

All the content of the journal, except where otherwise noted, is licensed under a Creative Commons License CC BY-NC. 